\title{
FULLY-AUTOMATIC BENCHTOP MACHINE FOR THE PRODUCTION OF NANOPARTICLE SUSPENSIONS
}

\author{
${ }^{1}$ Tobias BESSEL, ${ }^{1}$ Stephan BARCIKOWSKI, ${ }^{1}$ Friedrich WAAG \\ ${ }^{1}$ Technical Chemistry I, Center for Nanointegration Duisburg-Essen (CENIDE), University of Duisburg, \\ Essen, Germany, EU, friedrich.waag@uni-due.de
}

https://doi.org/10.37904/nanocon.2021.4317

\begin{abstract}
Developing and exploiting applications of functional nanomaterials often require colloidal nanoparticles with defined properties. Their production suffers from batch-to-batch variability as well as poor shelf life, and distributors demand high prices. The conditions for innovative application research must be improved by easier and more robust access to colloidal nanoparticles. A compact and fully automatic benchtop machine has been developed for quick, easy and reliable production of colloidal nanoparticles. The machine uses the method of laser synthesis of colloids, converting almost any solid of choice into colloidal nanoparticles. In addition, different dispersants and stabilizers can be dosed, if desired. An almost infinite range of colloids becomes available with one machine. We provide an insight into the operation of the machine and report in particular on the high performance efficiency of the laser-based synthesis. Furthermore, we highlight the benefits of using the device in R\&D of colloidal nanoparticles made possible by the technology.
\end{abstract}

Keywords: Ablation, productivity, PLAL, LASiS

\section{INTRODUCTION}

Inorganic nanoparticles represent an universal and essential resource with wide-ranging application relevance [1-3]. Many applications require non-agglomerated primary nanoparticles with a large and freely accessible surface area. These are generally prepared as suspensions by wet chemical methods using sometimes hazardous chemicals. Usually, surface-active agents are required to protect the particles from agglomeration, which in turn render access to the nanoparticle's surface (which determine their functionality) more difficult in applications. The syntheses are also labor-intensive and error-prone due to many closely timed steps in the procedure. All this makes application-oriented research with nanoparticles difficult and lengthy if one does the synthesis work oneself, or expensive and limited if one purchases the particles from distributors.

Automation enables more reliable and simpler manufacturing processes in many fields of technology. In the synthesis of nanoparticle suspensions, however, no complete commercial solution exists to date. We are therefore working on a fully automated laboratory machine, which will provide researchers and developers with the best access to colloidal nanoparticles.

In the machine, we use the well-established synthesis technique of laser ablation of solids in liquids [4]. The method offers three immense advantages over wet chemical methods: 1) It allows the preparation of highly pure nanoparticle colloids, 2) gives access to diverse combinations of nanoparticle material and dispersant, and 3 ) benefits from the high automation compatibility of laser technology. Until recently, the disadvantages of the method were the limited control of the particle size distribution, in particular also batch-to-batch-variations and the limited laser-power-specific ablation efficiency.

In this work, we report on the use of microchip lasers in laser-based colloid synthesis. These enable a compact size of the laboratory machine as well as sufficiently high productivity for the use of the device in research and development. This makes possible a significantly higher power efficiency in synthesis compared to other laser 
systems usually used for the synthesis of colloidal nanoparticles. Dittrich et al. demonstrated 5-times higher power-specific mass yield for an infrared, low-power, single-nanosecond microchip laser compared to a standard manufacturing laser that is typically used in laser-based nanoparticles synthesis [5].

We applied another microchip laser system in the synthesis of colloidal nanoparticles and compared the power efficiencies with previously reported ones. The laser system tested differs in particular in its laser wavelength $(532 \mathrm{~nm})$ from previously studied systems $(1.064 \mathrm{~nm})$. It is known from the literature that shorter wavelengths can generate smaller nanoparticles with narrower particle size distribution [6-9]. However, due to stronger attenuation effects by the nanoparticles on the incident laser beam, shorter laser wavelength usually decreases productivity and thus power efficiency $[10,11]$.

\section{EXPERIMENTAL}

A compact laser system (ONDA $532 \mathrm{~nm}$, BrightSolutions, Prado, Italy) with a wavelength of $532 \mathrm{~nm}$, a laser pulse length of $2 \mathrm{~ns}$, a repetition rate of $15 \mathrm{kHz}$, and a power of $3.6 \mathrm{~W}$ was used to synthesize colloidal nanoparticles. The power was measured behind the galvanometer scanner (PT-A20, PhenixTechnology, Guangzhou, China) used. The scanner was controlled by custom software. After the scanner, the laser beam was focused by a lens system with an absolute focal length of $50 \mathrm{~mm}$. The focused laser beam was directed onto the surface of rectangular metal plates. The platelets were placed in a chamber behind an anti-reflective coated glass plate followed by a flowing liquid layer.

Metal plates of Ag, Au and Pt (99.9 \%, R. Götze, Berlin, Germany) were used. In the case of Ag, the liquid used was an aqueous, $0.5 \mathrm{mM}$ trisodium citrate solution (analytical grade), and in the case of $\mathrm{Au}$ and $\mathrm{Pt}$, an aqueous, $0.5 \mathrm{mM}$ sodium chloride solution (analytical grade) was used. The fluids flowed through the chamber against gravity at a volume flow rate of $5 \mathrm{ml} / \mathrm{min}$. The generated nanoparticles were thus continuously carried out of the chamber and subsequently collected. For the performance efficiency study, the distance between the lens system and the target surface was adjusted to achieve maximum nanoparticle concentration. To determine productivity, we weighted the metal platelets after the experiment. The mass difference was then divided by the experimental duration of $20 \mathrm{~min}$. To determine the power efficiency, the productivity was divided by the measured laser power of $3.6 \mathrm{~W}$.

The optimal distance between the focusing lens system and the metal platelet for high productivity was determined by varying the distance in $0.25 \mathrm{~mm}$ steps. The nanoparticle concentration was determined qualitatively using a UV-Vis extinction spectrometer (Evolution 201, Thermo Fisher Scientific, Waltham, US). For this purpose, the colloids were diluted 1:2 with the appropriate dispersant and placed in quartz cuvettes. The absorbance was measured in the range of 230 and $900 \mathrm{~nm}$. All measurements were performed as differential measurements against cuvettes filled with the corresponding dispersant.

\section{RESULTS AND DISCUSSION}

We have recently reported performance efficiencies of the current prototype of our laboratory machine (Figure 1) in the synthesis of colloidal noble metal nanoparticles when using an infrared laser $(1,064 \mathrm{~nm})$ [12]. Below, we show corresponding data recorded using a green-wavelength laser beam source.

Since we worked with a focused laser beam, we first had to determine the distance between the lens system and the target surface at which the highest productivity was present. For this purpose, this distance was successively varied in $0.25 \mathrm{~mm}$ steps during the synthesis of the nanoparticles. At five different distances per metal, colloid samples were taken and analyzed with respect to their concentration by UV-Vis spectroscopy. Figure 2 (left) shows the corresponding spectra. The spectra show different extinctions as a function of distance from the productivity optimum. In the case of $\mathrm{Au}$ and $\mathrm{Ag}$, the characteristic surface plasmon resonance is also noticeable. From the spectra, the absorbance at a characteristic high-energy wavelength was extracted in the next step. Figure 2 (right) shows the data as a function of the distance between lens and 
target, normalized to the distance of maximized productivity. In the case of $\mathrm{Au}$ and $\mathrm{Pt}$, the best productivity was found at the same absolute position. For Ag, the position was $0.25 \mathrm{~mm}$ closer to the lens.
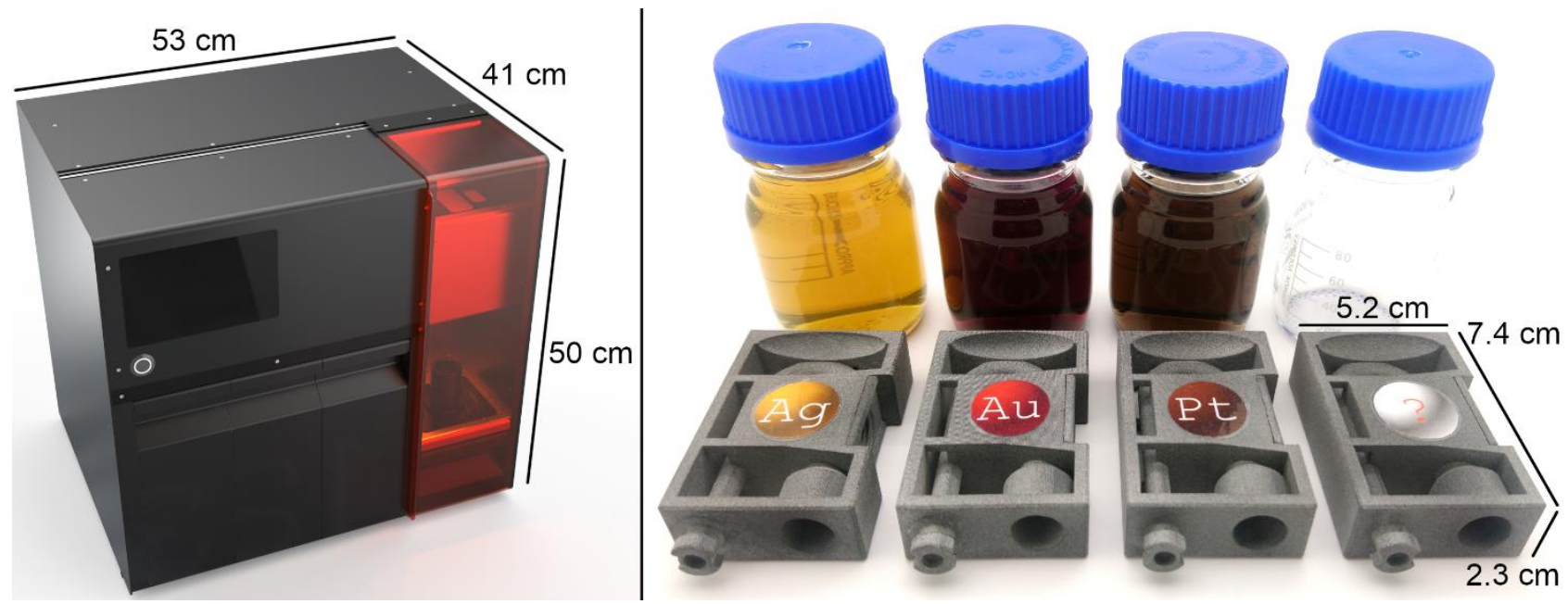

Figure 1 Laboratory machine prototype including its equipment: 3D model of the compact laboratory machine for the synthesis of colloidal nanoparticles (left) and colloidal nanoparticles of $\mathrm{Ag}, \mathrm{Au}$, and $\mathrm{Pt}$ as well as corresponding capsules for colloid production (right).
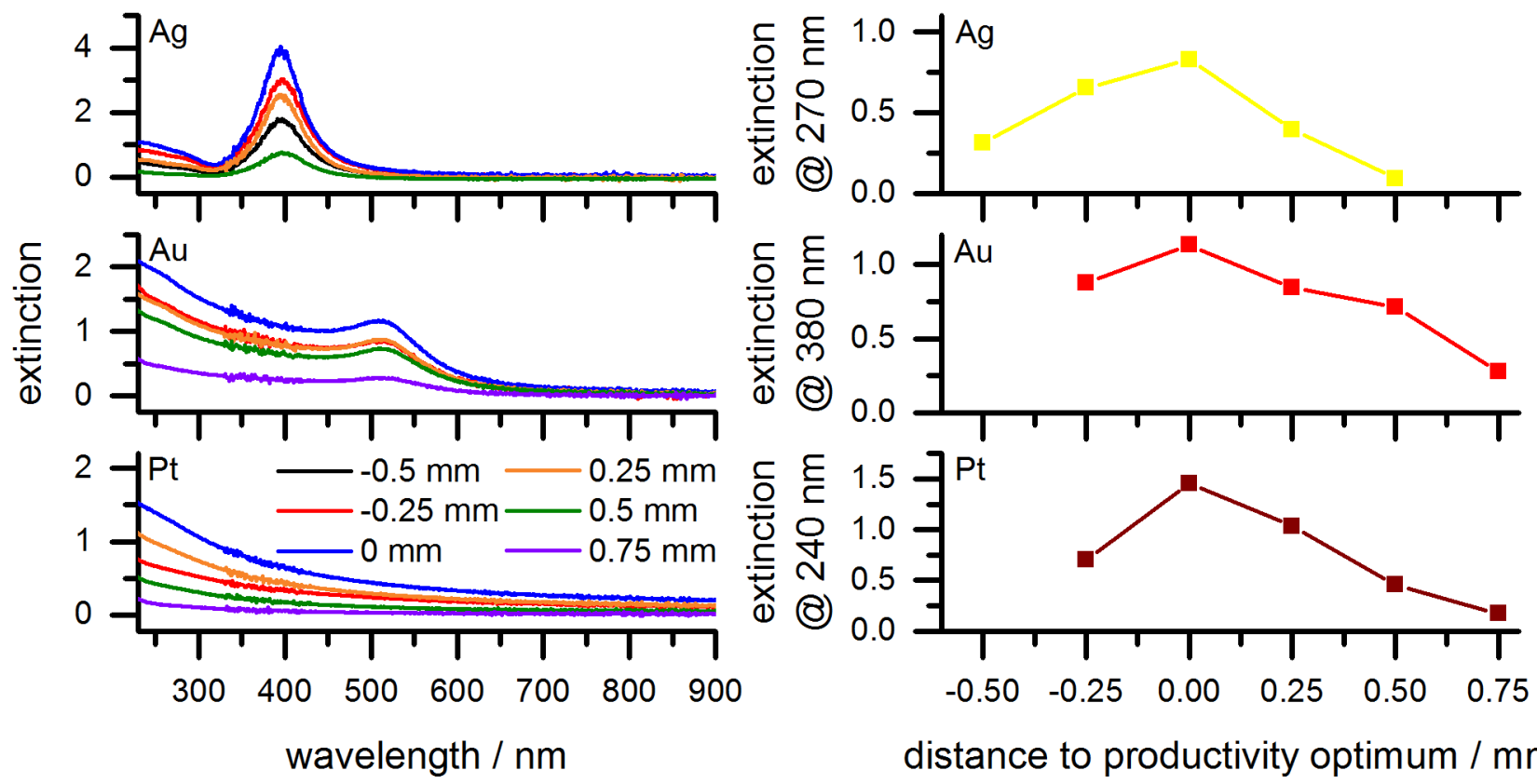

distance to productivity optimum / $\mathrm{mm}$

Figure 2 Dilution-corrected UV-Vis extinction spectra of Ag, Au, and Pt nanoparticle colloids produced at different distances to the optimum position for maximum productivity (left) and extracted extinctions of specific wavelengths versus the distance to the productivity optimum (right). More positive distance values represent shorter distances between lens and target.

We conducted ablation experiments with $\mathrm{Ag}, \mathrm{Au}$, and $\mathrm{Pt}$ at the respective optimal distance to determine the productivity and efficiency of nanoparticle generation with the compact laser system. Figure 3 (left) shows the achieved productivities of $33 \mathrm{mg} / \mathrm{h}(\mathrm{Ag}), 50 \mathrm{mg} / \mathrm{h}(\mathrm{Au})$ and $54 \mathrm{mg} / \mathrm{h}(\mathrm{Pt})$ compared to literature values. The 
productivities exceed those we were able to achieve in a previous study with an identical experimental setup but lower power and infrared laser system by factors of 3 to 4 [12]. However, the power of the green laser was about 7-times higher than the power of the infrared laser. Accordingly, we were able to achieve higher powerspecific efficiencies with the infrared laser system, as also shown in Figure 3 (right). In the case of $\mathrm{Ag}$, the efficiency is comparable when scattering is taken into account. For Au and Pt, however, the efficiency of the green laser system was significantly lower than that of the infrared one. This was probably because of the optical properties of the colloids. While the absorption and scattering properties of all colloids should have been negligible at $1.064 \mathrm{~nm}$, there were significant differences in the optical properties at $532 \mathrm{~nm}$. In particular, Au nanoparticles absorb green light due to their surface plasmon resonance. As Figure 2 (left) shows, the absorbance of the Pt colloid was 2-times higher than that of the Ag colloid. Despite the loss of efficiency due to the green laser wavelength, the green microchip laser achieved a 2-times higher efficiency in the synthesis of Au nanoparticles compared to a typical metal processing laser system, putting it in the same efficiency range as a high-end laser system designed specifically for the synthesis of colloidal nanoparticles.

The stronger interaction of laser light and nanoparticles in the case of the green laser could open up new possibilities in the manipulation of the particle size distribution [13-17]. Consequently, in the next step, it needs to be investigated to which extend in-process laser fragmentation as well as melting (or laser.induced aggregation) under the operating conditions of the automated synthesis system.
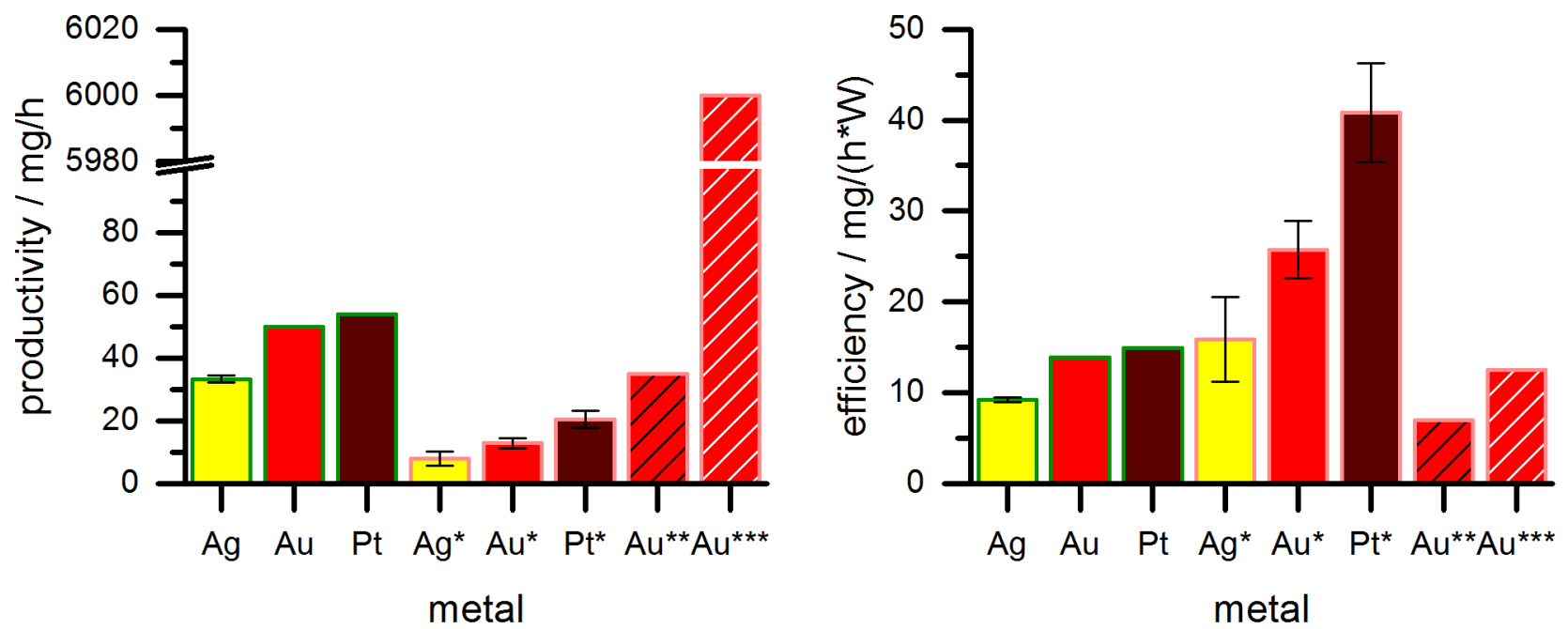

Figure 3 Productivity (left) and efficiency (right) of the compact laser-based synthesis of colloidal nanoparticles of $\mathrm{Ag}, \mathrm{Au}$, and $\mathrm{Pt}$. The error bar of the $\mathrm{Ag}$ sample represents the absolute deviation of two experiments to their average. *: Data of [12] recorded using a microchip laser system $(1,064 \mathrm{~nm}, 1 \mathrm{~ns}, 0.5$ W). ${ }^{* *}$ : Data of [5] recorded using a standard laser system (1,064 nm, $\left.5 \mathrm{~ns}, 5 \mathrm{~W}\right)$. ${ }^{* * *}$ : Data of [5] recorded using a high-end laser system (1,030 nm, 3 ps, 480 W).

\section{CONCLUSION}

By an automated laser synthesis system, nanoparticles for research and development can be produced easily, quickly, and reliably at the push of a button using a compact (i.e., benchtop) laboratory machine. The device can thus significantly accelerate application-oriented research based on nanoparticles in particular. The developed laser-based synthesis technology makes the automated machine a green and sustainable production device thanks to the greatly reduced use of chemicals compared to conventional synthesis methods. Note that atom yield (the consumed material that is converted into nanoparticles) of laser synthesis is $100 \%$, unreached by wet chemical synthesis. Further advantages for research and development result from the wide-ranging possibilities in material selection. For example, the machine can not only reliably produce 
nanoparticle colloids of standard materials, such as Au nanoparticles in aqueous suspension, but can also make innovative materials accessible, such as alloy nanoparticles for catalysis or biomedicine. The previous shortcoming of low efficiency of the laser-based method could be eliminated by using power-efficient microchip lasers. In the future, the possibilities of in-process size manipulation using green laser radiation will be investigated in detail.

\section{ACKNOWLEDGEMENTS}

We thank the European Union and the Ministry of Economic Affairs, Innovation, Digitalization and Energy of the German State of North Rhine-Westphalia for funding the development of the automated colloid maker to market maturity through the European Regional Development Fund in the STARTUP transfer.NRW program (AutoProNANO, EFRE-0400339). The START-UP transfer.NRW program supports researchers at public institutions in developing technologies to market maturity and thus in preparing a spin-off company. Please visit www.autopronano.eu for more information on our EUfunded project. We would also like to thank the German Federal Ministry for Economic Affairs and Energy for funding the prototype development in the Central Innovation Program for SMEs (Nanovollautomat, ZF4044504).

\section{REFERENCES}

[1] EALIA, S. A. M., SARAVANAKUMAR, M. P. A review on the classification, characterisation, synthesis of nanoparticles and their application. IOP Conference Series: Materials Science and Engineering. 2017, vol. 263, 032019.

[2] IJAZ, I., GILANI, E., NAZIR, A., BUKHARI, A. Detail review on chemical, physical and green synthesis, classification, characterizations and applications of nanoparticles. Green Chemistry Letters and Reviews. 2020, vol. 13, pp. 223-245.

[3] SOLANO, R., PATINO-RUIZ, D., TEJEDA-BENITEZ, L., HERRERA, A. Metal- and metal/oxide-based engineered nanoparticles and nanostructures: a review on the applications, nanotoxicological effects, and risk control strategies. Environmental Science and Pollution Research. 2021, vol. 28, pp. 16962-16981.

[4] KIM, M., OSONE, S., KIM, T., HIGASHI, H., SETO, T. Synthesis of Nanoparticles by Laser Ablation: A Review. KONA Powder and Particle Journal. 2017, vol. 34, pp. 80-90.

[5] DITTRICH, S., STREUBEL, R., MCDONNELL, C., HUBER, H. P., BARCIKOWSKI, S., GÖKCE, B. Comparison of the productivity and ablation efficiency of different laser classes for laser ablation of gold in water and air. Applied Physics A. 2019, vol. 125, p. 432.

[6] TSUJI, T., IRYO, K., WATANABE, N., TSUJI, M. Preparation of silver nanoparticles by laser ablation in solution: influence of laser wavelength on particle size. Applied Surface Science. 2002, vol. 202, pp. 80-85.

[7] KIM, J., REDDY, D. A., MA, R., KIM, T. K. The influence of laser wavelength and fluence on palladium nanoparticles produced by pulsed laser ablation in deionized water. Solid State Sciences. 2014, vol. 37, pp. 96102.

[8] CHEWCHINDA, P., TSUGE, T., FUNAKUBO, H., ODAWARA, O., WADA, H. Laser Wavelength Effect on Size and Morphology of Silicon Nanoparticles Prepared by Laser Ablation in Liquid. Japanese Journal of Applied Physics. 2014, vol. 53, 039201.

[9] GIORGETTI, E., MUNIZ-MIRANDA, M., MARSILI, P., SCARPELLINI, D., GIAMMANCO, F. Stable gold nanoparticles obtained in pure acetone by laser ablation with different wavelengths. Journal of Nanoparticle Research. 2012, vol. 14, p. 648.

[10] NICHOLS, W. T., SASAKI, T., KOSHIZAKI, N. Laser ablation of a platinum target in water. II. Ablation rate and nanoparticle size distributions. Journal of Applied Physics. 2006, vol. 100, 114912.

[11] SCHWENKE, A., WAGENER, P., NOLTE, S., BARCIKOWSKI, S. Influence of processing time on nanoparticle generation during picosecond-pulsed fundamental and second harmonic laser ablation of metals in tetrahydrofuran. Applied Physics A. 2011, vol. 104, pp. 77-82. 
[12] BESSEL, T., DITTRICH, S., GÖKCE, B., BARCIKOWSKI, S., WAAG, F. Automated synthesis of colloidal nanoparticles powered by microchip lasers. In: Lasers in Manufacturing (LiM 2021). Munich: Wissenschaftliche Gesellschaft Lasertechnik, 2021.

[13] WERNER, D., HASHIMOTO, S. Controlling the Pulsed-Laser-Induced Size Reduction of Au and Ag Nanoparticles via Changes in the External Pressure, Laser Intensity, and Excitation Wavelength. Langmuir. 2013, vol. 29, pp. 1295-1302.

[14] WERNER, D., HASHIMOTO, S. Improved Working Model for Interpreting the Excitation Wavelength- and Fluence-Dependent Response in Pulsed Laser-Induced Size Reduction of Aqueous Gold Nanoparticles. The Journal of Physical Chemistry C. 2011, vol. 115, pp. 5063-5072.

[15] CHUBILLEAU, C., LENOIR, B., MIGOT, S., DAUSCHER, A. Laser fragmentation in liquid medium: A new way for the synthesis of PbTe nanoparticles. Journal of Colloid and Interface Science. 2011, vol. 357, pp. 13-17.

[16] ISHIKAWA, Y., KOSHIZAKI, N., PYATENKO, A. Submicrometer-Sized Spherical Iron Oxide Particles Fabricated by Pulsed Laser Melting in Liquid. Electronic and Communications in Japan. 2016, vol. 99, pp. 37-42.

[17] PYATENKO, A., WANG, H., KOSHIZAKI, N., TSUJI, T. Mechanism of pulse laser interaction with colloidal nanoparticles. Laser \& Photonics Reviews. 2013, vol. 7, pp. 596-604. 